\title{
The Relationships of 90s College students' View on Love and Marriage, Cultivation Style and Social Support
}

\author{
Jie-Yi WU ${ }^{1, a}$, Ke-Ying WU $U^{2, b}$ \\ ${ }^{1}$ MianYang Normal University, Sichuan province, China \\ mywujieyi001@163.com
}

Keywords: 90s College student, View on marriage and love, Cultivation style, Social.

\begin{abstract}
The study adopts the research of undergraduates' views on marriage and love, Egma Minnen av Bardndosnauppforstran (EMBU),Social science research solutions(SSRS) of 286"90s College student", discusses the 90s College students' view on love and marriage, Cultivation style, Social support and their relationship, and trying to build the relationship between structure equation model, the results showed that: (1) 90s College students' view of marriage and love somewhere in between traditional and modern. Surprisingly, 90s College students' erotic choice is unusual traditional (2) Different grade has different ideas on the view of marriage and love, grade four get the highest score and grade three get the lowest.(3) There is significant different grades on the view of marriage and love between girls and boys. Girls are more traditional than boys. (4) In the aspect of student origin, we can see the remarkable difference in different students. As a whole, the view on marriage and love of country students are the most traditional, town students are the most modern. (5)Student in different majors have the different ideas on the view of marriage and love. Liberal arts students are the most traditional, maybe a large number of them are girls were the reason. (6) Influences such as parental marital status and relationship or different inhabitancy circs have little impact on 90s College students' view on marriage and love. (7) Cultivation style and Social support can't directly affect attribution way sense of 90s College students' view on marriage and love, but they can impact of erotic choice directly. We can see 90s College students' Cultivation style and Social support attribution way a close relationship with their erotic choice on the view of their marriage and love.
\end{abstract}

\section{Why this topic}

Love is a common phenomenon in major college universities. Marriage issues are also a hot topic in the student population. These studies have shown that post-post 90s showing love and marriage generally blind and irrational situation [1]. "Post 90s" as "Post 80s" derivative term, refers to Chinese citizens who were born in January 1, 1990 to December 31, 1999. Unlike the post 80s, by the far-reaching impact of traditional moral values, post 90s have their own way in fashion, personality worship, which likes the maverick. Recent survey shows that there are many hidden dangers [2], such as "money worship" and "seeking nurturing event", "married after graduation" phenomenon. Faced with these questions, it is urgent to carry out in-depth investigation, timely prevention, and thorough research.

\section{Research Process}

\section{Research method}

The study used questionnaires to post 90s were performing marriage concept study parenting styles and social support. Later on the findings, we use random checks in the form of interviews to explore the causes of the problem.

\section{Research subject}

Subjects were selected from Mianyang Normal University, Southwest University of Science and Technology, Southwest University of Finance and Economics Tianfu, Chengdu Vocational and 
Technical College, Chengdu University of Technology, Leshan Teachers College, Jimei University, Dalian Maritime University. To ensure that subjects are representative, random sampling, were selected from freshman to senior subjects 300,300 questionnaires distributed,286 valid questionnaires were recovered.

\section{Research tool}

How to evaluate. Adopted Su Hong'concept questionnaire (CMLCQ), project selection referring to the questions of the questionnaire prepared by many scholars, combined with the actual living conditions of college students, a total of 34 questions, 7 main factors. Internal consistency coefficient factor between $0.5840-0.8570,0.3298-0.8315$ split-half reliability between the various components and factors associated with the questionnaire scores in between 0.307-0.680, $0.093-0.313$ between the inter-related factors, with better the reliability and validity. All items using Likert-type five o'clock points system, and the use of radio forced-choice form, the degree of compliance by college students into five ratings, which "absolutely" five points, "agree" four points, "not sure "three points," disagree" 2 points," totally inconsistent "1 point. A higher score indicates more conservative view of marriage.

Assessment of parenting styles. The research adopted EMBU Chinese version which revised by Dongmei Yue et al. Father and mother parenting style contains two subscales, a total of 66 projects. Father's parenting style has six factors: care to understand, severe punishment, refused to deny favoritism, excessive interference, and overprotection. Mother's parenting style has five factors: care to understand, severe punishment, refused to deny favoritism, excessive interference protection. The four Likert scale scores were asked to make a rating between $1-4$. The scale has good reliability. Father internal consistency coefficient table are: 0.8994,0.8575,0.7315,0.6356,0.7819,0.6489. Mother internal consistency coefficient table are: $0.8771,0.8617,0.8103,0.6147,0.8075$. Numerous studies have shown it has good construct validity. If the subjects were tested for a score higher than the norm factor term averages, then were tested on the performance of the corresponding parenting style.

Assessment of social support. Adopted Social Support Scale which designed by Shuiyuan Shaw. Social support and that of ten entries per meter, which is divided into 2,6,7 objective support questions and rated the subjective ratings of support into question and 1,3,4,5, utilization of support is the title of $8,9,10$ and. The internal consistency of the scale factor is $0.890-0.940$, test-retest reliability was 0.920 . Load factor for each project between $0.46-0.89$, three factors explain the rate of up to $53.08 \%$, indicating that the scale has high construct validity.

\section{Research Procedure}

The questionnaires were carried out by the students who majored in application of psychology. Fill in the questionnaire is anonymous, and ultimately collected 286 valid questionnaires.

The data processing: respectively use EXCEL2003 and SPSS13.0, SPSS17.0 for data entry and processing.

\section{Result}

\section{Dimensions and characteristics of post 90s Marriage Concept presents}

Comparison between dimensions and characteristics of post 90s Marriage Concept. According to descriptive statistics analysis, each factor score by descending order are: sexual choice concept $>$ marital fidelity view $>$ Marriage Values $>$ Marriage from subjective $>$ Love Motivation $>$ Marriage tendency $>$ Marriage role concept. The results demonstrated that post 90 s between love and marriage intermediate level traditional concept of sexual choices on the dimension and did not as open and irresponsible as the public imagination, but tend to be conservative.

Differences grades on Marriage Concept College. With grades as independent variables to Marriage Concept score as the dependent variable and its dimensions do independent samples ANOVA factor analysis, the results showed that post 90s in grades Marriage Views significant 
difference,the performance of senior grade group scored significantly higher the other three grades, while the large sophomore year with a statistically significant difference in the concept of marriage problems, the lowest score junior year,most open marriage concept.

Differences Marriage Views on whether they are one child or not. Use whether the subject is the only child as the independent variables, college students Marriage Concept and its dimensions as the dependent variable, independent samples T-test results show that if the only child of the post 90s on the Marriage Outlook overall impact is not significant. However, the only child of a statistically significant difference on the impact of sexual orientation and marital college choices.

Differences marriage view on learning subject of college. The learning categories as independent variables, the marriage view as the dependent variable and the factors do independent samples ANOVA factor analysis,post 90s in the subjects of love and marriage concept category overall difference was not significant,but in the individual factors preached significant difference.Post 90s in medical class and art class adhere more traditional male dominance marriage, the students in liberal arts students like open marriage, marital relations value equality.On marriage tendency, art students view marriages tend to be more intense than other disciplines students,and liberal arts,science,medicine, engineering class students were no significant differences in the marriage tendencies.

In love motivation factor,medical class students love the most diverse motives, views on the value of marriage,class differences between students of various disciplines remarkable performance art students to imagine the ideal of marriage,the most realistic science students, on the scores of art category $>$ medical $>$ Engineering $>$ Arts $>$ science.In view of the decision on the marriage,the various disciplines are also significant differences,one of the most conservative liberal arts students, more stick because of love,artistic disciplines students the most open, the reasons are more of a choice, but overall still tend to discipline between conservative and traditional.

Differences in the concept of marriage views in different parents' marital status and living conditions. Parents' marital status, living situation as independent variables, Marriage Views of post 90s each dimension as the dependent variable to do a single dependent variable multivariate analysis of variance. Parents' marital status and living conditions were tested for impact on the overall concept of marriage and the dimensions of the post 90 s students the difference was not significant. But post $90 \mathrm{~s}$ parents are divorced or separated parents' marriage than a normal test subjects were more eager to families with warmth and support, and in the more traditional roles of marriage, marriage tends to be more intense, more diverse motives of love and so on.

\section{College students Marriage Concept, parenting styles, gender differences in social support and family}

Students' Marriage Concept in post 90s, the parenting styles, gender differences in social support. View gender as independent variables to assess social support score, parenting styles and dimensions of each concept of marriage as the dependent variable. T-test results showed that: post 90 s of different genders were no significant differences in the total social support. Post 90s of different genders concept of choice in marriage, marital roles, marital significantly different from the subjective, no significant differences in the marriage tendencies, values, loyalty and love, motivation, on the whole concept of the marriage was very significant difference. Concept of choice is more open to boys than girls in the marriage relationship exhibited still want to maintain traditional male dominance, the choice of marriage than girls are more passive, on parenting styles, parents for post 90s of different sexes in " punished severely ", " excessive interference " ,significant differences exist on the three factors," refused to deny " the parents of the boy described the new era more stringent requirements, but on the emotional understanding and preference factors, no significant differences in gender.

Students' Marriage Views in post 90s, the parenting styles, social support, geographical differences in the family. Families living in different regions of the grouping variable to post $90 \mathrm{~s}$ social support, as well as the dimensions of Marriage Views of parenting styles do independent samples as the dependent variable coefficient of variation of a single factor analysis. As can be seen 
from the results and after comparison, who lives in a different area after college. There were significant differences in the degree of social support, the performance of post 90s after the level of social support from rural areas is significantly higher than 90 college towns and cities, and urban and college no significant difference in the level of social support town 90 . Factor in the concept of marriage, city college students, there are autonomous in marriage and marriage tends to rural students and urban significant difference, and the role of urban students in marriage and marriage values and cities, significant differences between rural students. Throughout the post $90 \mathrm{~s}$ in the family who lives in parenting style data display area, there are significant differences about rural parents in the preference factor and urban town's parents. The mothers in Cities and towns compared with mothers in rural have huge differences in punishment style.

Students' Marriage Concept in post 90s, parenting styles, social support differences in parents' marital relationship. Marriage Concept investigated post 90s,parenting styles, social support, differences in the quality of the marital relationship to parents' marital relationship grouping variable to post 90s Family Education levels, social support and marriage concept scores and Marriage Concept each dimension as the dependent variable, do independent samples ANOVA factor analysis. The results show that the quality of the marital relationship parents have significant differences in the level and impact of parenting style of post 90s of social support, expressed as parents' marital relations were tested better than their parents marital relationship is poor social support, get tested more, after comparison shows "Good > General > poor." On the other hand, a good relationship with their parents than the parents' relationship is tested subjects suffered poor parenting styles more democratic, and more emotional love and understanding ,less punitive blame.

\section{The concept of post 90s college students' marriage, parenting styles, the relationship between social supports}

The concept of post 90s marriage, parenting styles, the relationship between social supports. Using Spearman correlation analysis, post 90s explore related social support, parenting styles and Marriage Concept between its various dimensions, the results show the same level of social support, family education related to the way the whole concept of marriage after post 90s students not significant. But between parenting styles with the level of social support was significantly related.

As can be seen from the results, level of social supporting post 90 s with their marriage concept of sexual choice, marital loyalty was a significant positive correlation $(\mathrm{P}<0.01)$. On the other hand, social support and marital orientation, marital value was significantly negatively correlated ( $\mathrm{P}$ $<0.01)$.

Differences in social support students and each factor on the post 90s under different parenting styles. In accordance with the normal standard of $27 \%$ to $27 \%$ as a critical point, combined with the subjects in the Family Education distribution of scores, post $90 \mathrm{~s}$ will be divided into good family upbringing, moderate, poor three groups. Family Education group represents the poor more than blame, punishment, refused to care less understood, moderate group represents both punitive parenting styles refused to have a certain understanding of love, caring and good group represents more than understanding. Universal analysis of variance, derived from the results of different parenting styles, college students under the support of the community and its dimensions significant differences between groups. Poor performance of the group in an objective level of support and overall support was significantly higher than the middle group and a good group and the low level of inter- group difference was significant, as demonstrated by a good group> moderate group> poorer groups. Description of the different parenting styles, and has a significant impact on the children of subjective and objective support experience, democratic, caring understanding type of parenting styles children growing up experience better social support, 90 different parenting styles in the growth of college students subjective support and utilization of support showed a significant difference between the groups on two more subjective factors.

Social Support Marriage Concept differences of each factor under different levels of post 90s'group. Social Support Scale based on the definition of the level of support, combined with the subjects in the distribution of social support, social support is divided into high, medium and low 
three groups. This is defined as more than 40 points higher grouping, indicating that more adequate social support, ranging between 20-40 minutes is defined as the grouping that represents a certain degree of social support, defined as less than 20 points lower grouping, indicating subjects were lack of social support. Analysis of variance in post 90 s of different levels of differences in their outlook and their factors on marriage are significant. According to the results, the level of social support for post 90s in sex marriage concept choice, marital roles, marital orientation, marital loyalty and affect the value of the difference was statistically significant marriage.

Marriage Views of post 90s and factor differences on different parenting styles. Similarly, the combination was tested in the specific circumstances of parenting styles, and post 90 s will be divided into good family upbringing, moderate, poor three groups. Unvaried analysis of variance investigated post 90 s under the different parenting styles on the concept of marriage and its various dimensions of difference circumstances. The results can be seen in different parenting styles on post 90s overall impact was not significant, but the concept of neutral marriage choices, two independent factors affecting marital differences significantly.

Post 90s view sex choices, parenting styles, regression analysis of social support. Marriage Concept study of sexual choice concept, parenting styles, relationships among social support, we will parenting styles and social support as the concept of sexual choice criterion variables predicted to gradually enter the method of regression analysis showed that, parenting styles first into the regression equation, social support, and then into the regression equation, indicating that parenting styles and social support were significant variables in predicting the concept of marriage choices neutral outlook multiple correlation coefficient was 0.291.contrast, family upbringing way to predict sex marriage concept in view of better choices, which explain the amount of $4.5 \%$, while the amount attributed to explain the way to $4 \%$, the joint predictive power of the two variables is $8.5 \%$. From the regression analysis of variance test results of the regression equation to see, $F$ value reaches a significant level $(\mathrm{p}<0.001)$, indicating that the regression equation is meaningful. In addition, the regression coefficient significant test $\mathrm{T}$ test showed that parenting styles on the concept of sexual choices play a significant negative predictor and the community support for the concept of sexual choices from significant positive predictor, which draws the following regression equation:

Sex choice concept $=-0.222 *$ Family Education $+0.199 *$ social support

\section{Conclusions}

In this study, the following conclusions:

Marriage Views of post 90s in each dimension are unbalanced. In grades, the variables show significant differences. But for whether the only one child, the subject categories, parental marital status and living conditions of the impact on the overall difference was not significant, but in the individual factor on preached significant differences.

Post 90s of different gender and social support level was not significant. Marriage was no significant difference in terms of concept, a different family area post 90 s love and marriage show significant differences, the town most open, the most conservative rural areas. Significant differences in the level of social support, expressed as: City > Rural > towns. Family Education difference was not significant, but the posts 90 s who are from the city are more stringent, and more care to understand the countryside.

Post 90s parenting styles associated with significant levels of social support, no significant correlation between the two and marriage concept. However, the level of social support in Sex Marriage Concept choice, marriage was a significant positive correlation between loyalties. Family Education and Marriage Concept of sexual choices significantly correlated.

Different parenting styles post $90 \mathrm{~s}$ a significant difference in the level of social support, no significant difference in marriage concept, different levels of social support was not significantly different concept of marriage, but the overall higher level of social support were tested, more in line with its concept of marriage social desirability .

Post 90s parenting styles, social support concept for the 90 college students have a choice of sex certain prediction. 


\section{Education proposal:}

The University should hold a range of courses related in "love, sex and marriage" and other related university courses, to make the topic which the people have been avoid talking about in public. This proposal might reduce the students' feeling about love and marriage for the blind and overly sensitive, and prevent failure in love with negative behaviors (such as poor venting, self-closing, revenge, suicide, etc.). What's more the courses will establish a correct concept of sexual health education.

Modeled on the current middle and high school education, the University should establish a "home school" sites, forums, or hotlines, to strengthen school interactive contact with the parents. The parents' joint supports will made our society attached great attention, and guide the growth and development of college students at the University. At the same time, it can also coordinate the psychological problems many college students might occur in the school.

Held a variety of campus activities and fellowship in university, or with other university or communities to enhance their communication ability and enrich their daily school life. Coordinate with government or cooperation to set up many employment opportunities for the graduates, to support them go through the transition and build a good platform to the society.

\section{Reference}

[1] He ying, Cao hao, Jin Xiaohong. The new research issues of contemporary college students' love, Journal of Higher Correspondence Education (Philosophy and social science version), 2009, 22(8): 100-103.

[2] Mao Tingting, Zhang Yin."How to build a correct marriage concept for post 90s",Education Administration,2011,1(II): 127.

[3] Su Hong, Reng Yongjin. Domestic and foreign research review of college students'view of marriage and love [J]. Journal of Henan Teachers College of Technology (occupation and education edition), 2008,2:81-83.

[4] Hu Liren, Xu Yin, Tan Qiuhao. Low grade marriage outlook and concept in medical students [J], Health Psychology Journal, 2000, 8(6):698-701.

[5] Zhao Bingiie. Investigation and study of college students'view of marriage and love [J]. Chinese Journal of Clinical Psychology,2002,10(2):111-113.

[6] Su Hong. Structure of College Students' view of love and marriage, research on the characteristics and influence factors. Master's degree thesis of Southwestern University, 2006,5.

[7] Li Yongfang, Ni Zhijun, Niu Ruixian, etc. Investigation and Reflection on Contemporary College Students Outlook on love and marriage [J] Sexology in China, 2009, 18(1):14-17.

[8] Zhou Zhenyan. Study on Preparation and education strategies questionnaire of Chongqing college students'marriage, Master's degree thesis of Southwestern University, 20090401.

[9] Ji Qiufa. Beijing youth's marriage -- An Empirical Analysis of survey, Youth Studies, 1995,7:19.

[10] Huang Xiting,Zheng yong.Contemporary Chinese college students psychological and educational characteristics [M], Shanghai Educational Publishing House, 2002.

[11] Liu Yali, Characteristics and guide of the contemporary college students view of love and marriage, ideological education,2003,10:17-20.

[12] Brantley A, Knox D, Zusman M E, When and why gender different in saying"I love you" among college students [J]. College Student Journal, 2002, 36(4):614-615.

[13] Paige D. Martin. \& Martin M. Adolescent premarital sexual activity cohabitation and attitudes toward marriage, Adolescence.2001.36 (143):601 - 609. 
[14] Salts, Connie J, Seismore, melisa D, Lindholm,Byron W, Smith\&Thomas. Attitudes toward marriage and premarital sexual activity of college freshmen [J].Adolescence, 1994, 29(116): 775779.

\section{Author introduction}

Jie-Yi Wu 1957 - Chengdu, Sichuan province Associate professor

The research direction: personality psychology/students mental health education

Ke-Ying Wu 1989 - Chengdu, Sichuan province Teacher

Major: student mental health education

Contact address: Mianyang Normal University,Sichuan province,China.

Telephone: 18981146032

E-mail: 584618279 @qq.com mywujieyi001@163.com

Code: 621000 